\title{
miR-20b overexpression is predictive of poor prognosis in gastric cancer
}

This article was published in the following Dove Press journal:

OncoTargets and Therapy

24 July 2015

Number of times this article has been viewed

\section{Tong-min Xue* \\ Li-de Tao* \\ Miao Zhang* \\ Guang-cai Xu \\ Jie Zhang \\ Pei-Jian Zhang}

Institute of General Surgical Research, Second Affiliated Hospital, Yangzhou University, Yangzhou, Jiangsu, People's Republic of China

*These authors contributed equally to this work
Correspondence: Pei-Jian Zhang Institute of General Surgical Research, Second Affiliated Hospital, Yangzhou University, Yangzhou, Jiangsu 225002, People's Republic of China Email yzu.edu.pjz@I63.com
Background: miR-20b has been shown to be aberrantly expressed in several tumor types. However, the clinical significance of miR-20b in the prognosis of patients with gastric cancer (GC) is poorly understood, and the exact role of miR-20b in GC remains unclear.

Materials and methods: The expression of miR-20b was detected in 102 patients with GC by a SYBR Green assay and was compared with the expression in matched adjacent normal tissue specimens. The aim of the present study was to investigate the association of the expression of miR-20b with the clinicopathological characteristics and the overall survival of patients with GC as analyzed by Kaplan-Meier analysis and Cox proportional hazards regression models.

Results: Our results showed that miR-20b expression was upregulated in GC tissue compared with normal mucosa $(P=0.00)$. Furthermore, miR-20b expression was positively correlated with advanced lymph node metastasis $(P=0.041)$, tumor node metastasis stage $(P=0.000)$, and deeper and distant metastasis $(P=0.031)$. The overall survival rate of patients with GC was significantly lower in those whose tumors expressed high levels of miR-20b mRNA compared with those whose tumors expressed low levels of miR-20b mRNA $(P=0.019)$.

Conclusion: miR-20b may serve as a potential molecular marker for the prognosis of GC.

Keywords: miR-20b, microRNA, cancer, clinicopathology

\section{Introduction}

Gastric cancer (GC) is the fourth most common cancer and is associated with an extremely poor prognosis, and as a result, GC remains the second leading cause of cancer mortality worldwide. ${ }^{1,2}$ Despite considerable studies on the tumorigenesis and progression of GC, the pathogenesis of this complex disease is poorly understood. Because a more favorable outcome of GC is closely related to how early the disease is diagnosed and subjected to proper treatment, efficient diagnostic methods, estimation of prognosis, and effective therapeutic strategies are urgently needed in clinical practice in regard to GC. ${ }^{3}$ Thus, it is of vital clinical value to identify and characterize the precise molecular mechanism involved in the development and progression of GC. ${ }^{4}$

miRNAs are a class of small non-coding RNA molecules that regulate gene expression by binding to partially complementary recognition sequences of target mRNAs. They function in either the repression of miRNA translation or the cleavage of target miRNA and RNAs that are highly conserved among species. ${ }^{5-8}$ In recent years, an increased number of studies have indicated that miRNAs have crucial functions in specific cellular processes such as differentiation, morphogenesis, and tumorigenesis and that miRNAs may also be considered oncogenes or tumor suppressors. ${ }^{9-13}$

Some studies have shown that miR-20b is deregulated in several types of cancers ${ }^{14-18}$ and that the upregulation of miR-20b correlates with a worse prognosis; all of these studies indicated that miR-20b acts as a tumor promoter. ${ }^{17,19-23}$ Currently, the clinical significance of miR-20b in the prognosis of patients with GC is poorly understood, and 
the exact role of miR-20b in GC remains unclear. Here, we investigated the association between miR-20b expression and the clinicopathological parameters of patients with GC.

\section{Materials and methods}

\section{Tissue samples}

In all, 102 samples of GC tissues were obtained from patients and were collected by the Institute of General Surgical Research, Second Affiliated Hospital, Yangzhou University, Jiangsu, People's Republic of China. In addition, non-tumorous gastric mucosa tissues that were located more than $3 \mathrm{~cm}$ away from the tumors were obtained from all 102 patients and used as controls. The clinicopathological characteristics and parameters are shown in Table 1. None of the patients with GC received any previous treatments such as radiation therapy, chemoembolization or chemotherapy.

\section{Ethics statement}

The study was approved by the Institute of General Surgical Research, Second Affiliated Hospital, Yangzhou University, Jiangsu, People's Republic of China. All specimens were

Table I The comparison between miR-20b expression and the clinicopathological features of GC

\begin{tabular}{|c|c|c|c|}
\hline Variable & $\begin{array}{l}\text { Patients, } \\
n(n=\mid 02)\end{array}$ & $\begin{array}{l}\text { miR-20b } \\
\text { expression } \\
(\text { Mean } \pm \text { SEM) }\end{array}$ & $P$-value \\
\hline \multicolumn{4}{|l|}{ Age (years) } \\
\hline$\leq 57$ & 54 & $1.161 \pm 0.06149$ & 0.725 \\
\hline$>57$ & 48 & $1.132 \pm 0.05208$ & \\
\hline \multicolumn{4}{|l|}{ Sex } \\
\hline Male & 71 & $\mathrm{I} .12 \mathrm{I} \pm 0.0504 \mathrm{I}$ & 0.459 \\
\hline Female & 31 & $1.186 \pm 0.06615$ & \\
\hline \multicolumn{4}{|c|}{ Tumor size $(\mathrm{cm})$} \\
\hline$\geq 3$ & 66 & $1.119 \pm 0.05335$ & 0.316 \\
\hline$<3$ & 36 & II.204 \pm 0.05820 & \\
\hline \multicolumn{4}{|c|}{ Invasion depth } \\
\hline $\mathrm{TI} / \mathrm{T} 2$ & 50 & I.156 10.06777 & 0.988 \\
\hline $\mathrm{T} 3 / \mathrm{T} 4$ & 52 & $1.156 \pm 0.04220$ & \\
\hline \multicolumn{4}{|c|}{ Lymph node metastasis } \\
\hline Yes & 67 & $1.285 \pm 0.08042$ & $0.04 I^{*}$ \\
\hline No & 35 & $|.08 I \pm 0.0598|$ & \\
\hline \multicolumn{4}{|c|}{ Pathological grade } \\
\hline $\mathrm{GI} / \mathrm{G} 2$ & 66 & $1.139 \pm 0.07203$ & 0.557 \\
\hline G3/G4 & 36 & I. $187 \pm 0.04520$ & \\
\hline \multicolumn{4}{|l|}{ TNM stage } \\
\hline I-II & 55 & $1.3020 \pm 0.04644$ & $0.000 *$ \\
\hline III-IV & 47 & $0.9976 \pm 0.05802$ & \\
\hline \multicolumn{4}{|c|}{ Distant metastasis } \\
\hline Positive & 53 & $1.220 \pm 0.05278$ & $0.03 I^{*}$ \\
\hline Negative & 49 & $1.043 \pm 0.06300$ & \\
\hline
\end{tabular}

Note: $* p<0.05$.

Abbreviations: GC, gastric cancer; TNM, tumor node metastasis; SEM, standard error of the mean. handled and de-identified according to ethical and legal standards. We obtained written informed consent from all participants involved in our study.

\section{Hematoxylin-eosin (HE)}

To evaluate the GC tissues and adjacent normal tissue specimens, HE staining was performed using the sections of GC and normal tissue. The paraffin sections were conventionally dewaxed and rehydrated, followed with staining in hematoxylin for 5 minutes, color separation with $1 \%$ hydrochloric acid alcohol for 5 seconds, and staining in eosin for 2 minutes. After that, the paraffin sections were dehydrated by graded series of ethanol, cleared by xylene, and finally sealed with neutral gum.

\section{Reverse transcription quantitative polymerase chain reaction (RT-qPCR)}

Total RNA from cell lines or tissue samples was extracted using a mirVana miRNA Isolation Kit (Ambion, Austin, TX, USA) following the manufacturer's instructions. The purity and concentration of the RNA samples were assessed by standard spectrophotometric methods in a 2100 Bioanalyzer (Agilent Technologies, Santa Clara, CA, USA). Briefly, $5 \mathrm{ng}$ of RNA was added to the RT reaction, and then, the cDNA served as the template for amplification during PCR with sequence-specific primers (Sangon Biotech, Shanghai, People's Republic of China) using a SYBR PrimeScript miRNA RT-PCR kit (Takara Biotechnology Co. Ltd, Dalian, People's Republic of China). All reactions were run in triplicate in an iCycler iQ Multicolor Real-Time PCR Detection System (BioRad Laboratories Inc., Hercules, CA, USA). Small nucleolar RNA GAPDH was used as an internal standard for normalization. Each sample was run in duplicate for analysis. The change in mRNA levels in GC tissues relative to the matched normal liver tissues was calculated with the $2^{-\Delta \Delta \mathrm{Ct}}$ method, where $\Delta \Delta \mathrm{Ct}=\Delta \mathrm{Ct} \mathrm{GC} /$ normal tissues and $\Delta \mathrm{Ct}=\mathrm{Ct}_{\text {miR-20b }}-\mathrm{Ct}_{\mathrm{GAPDH}}$.

For miR-20b, the primers were as follows (Sangon Biotech, Shanghai, People's Republic of China): forward, 5'-TGTCAACGATACGCTACG A-3' and reverse, 5'-GCTC ATAGTGCAGGTAGA-3'. GAPDH forward, 5'-GTG GTCCAGGGTTTCTTACT-3' and reverse, 5'-GTTGTCT CCTGCGACTTCA-3'.

\section{Statistical analysis}

All statistical analyses were performed using GraphPad Prism 6 software (GraphPad Software, Inc., La Jolla, CA, USA) and SPSS software 18.0 (SPSS Inc., Chicago, IL, 
USA). Data are presented as the mean \pm standard deviation. The significance of the differences was evaluated by Student's $t$-test. The $\chi^{2}$ test was used to compare the high expression rate of miR-20b in GC tissues of patients with different clinicopathologic characteristics. The postoperative survival rate was analyzed with the Cox regression method and the Kaplan-Meier method, and differences in survival rates were assessed with the log-rank test. Differences with $P$-values $<0.05$ were considered statistically significant.

\section{Results}

\section{HE staining}

HE staining has allowed assessment of microscopic grading of GC studied (Figure 1). All 102 GC tissues were confirmed for $\mathrm{GC}$.

\section{miR-20b is upregulated in GC tissues}

Based on the RT-qPCR, we found that miR-20b expression levels were significantly upregulated in GC cancer tissues (1.155 \pm 0.03981$)$ compared with adjacent non-cancerous tissues $(0.5536 \pm 0.0355)(P<0.0001$, Figure 2$)$.

\section{Correlation between the levels of miR-20b expression and the clinicopathological characteristics of patients with GC}

The miR-20b expression levels were classified as high or low in relation to the median value. In addition, we found that the expression levels of miR-20b in patients with GC were not significantly correlated with sex, age, tumor size, invasion depth, and pathological grade $(P>0.05$; Table 1). However, when we compared the expression of miR-20b and lymph node metastasis, tumor node metastasis (TNM) stage, and distant metastasis, a significant difference was observed (Figure 3).

\section{miR-20b expression and postoperative survival}

Kaplan-Meier survival curve and log-rank test were used to analyze the correlation between miR-20b expression and the overall survival (OS) of GC patients. The OS rate of the patients with GC was significantly lower in patients whose tumors expressed high levels of miR-20b mRNA compared with those whose tumors expressed low levels; this means that high miR-20b expression might be correlated with poor prognosis of GC patients ( $P=0.019$; Figure 4$)$. We also used univariate and multivariate Cox model analyses to determine the correlation between miR-20b expression and the OS of patients with GC. According to a univariate analysis, lymph node metastasis, TNM stage, distant metastasis, and miR-20b expression were statistically significant prognostic factors (Table 2). A multivariate analysis confirmed that TNM stage and miR-20b expression were significant and independent predictors of poor survival of patients with GC (Table 3).

\section{Discussion}

In previous studies, many miRNAs have been confirmed to contribute to the initiation and progression of cancer such as GC. As further in-depth studies were conducted, more and more miRNAs have been shown to function in the regulation of the development of GC. Furthermore, it has been shown that miRNAs can function as tumor suppressors or oncogenes, can repress the expression of important cancer-related genes, and might prove to be useful biomarkers in the diagnosis and treatment of cancers. ${ }^{24}$ The important role of miRNAs in GC tells us that the understanding of the function of miRNAs will
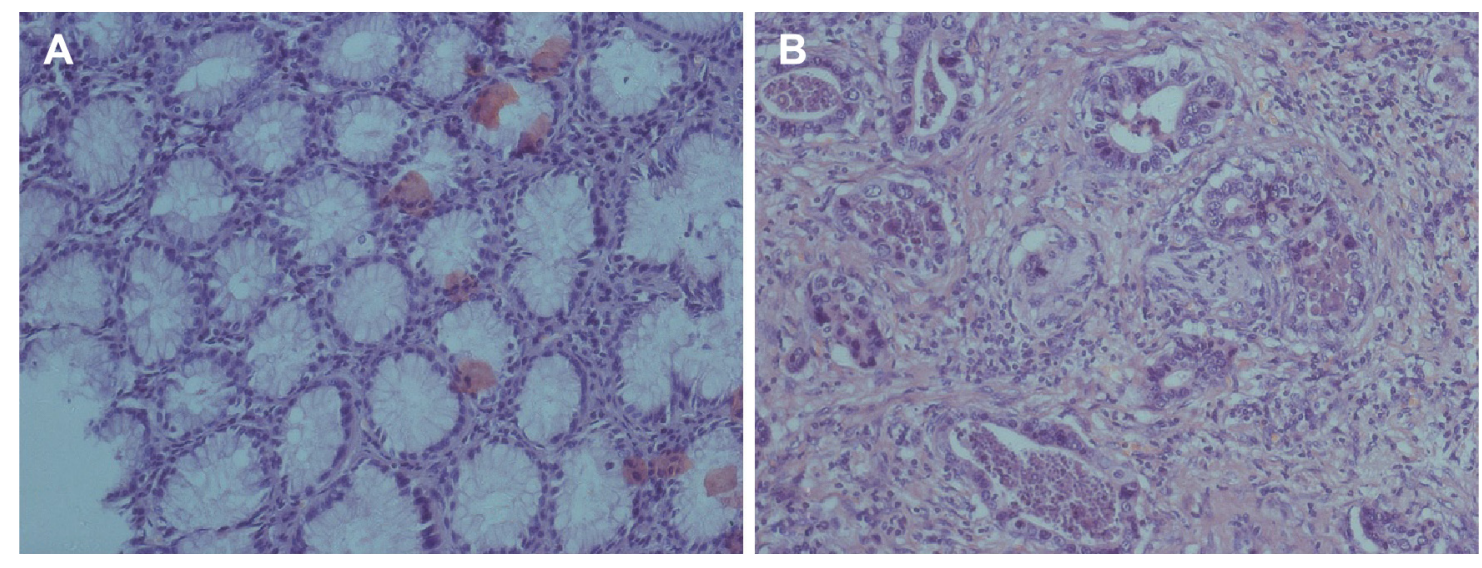

Figure I HE staining was performed using the sections of normal tissue and GC.

Notes: (A) The normal tissue specimens; (B) gastric adenocarcinoma (Hematoxylin-eosin staining, $\times 200$ ).

Abbreviations: HE, Hematoxylin-eosin; GC, gastric cancer. 


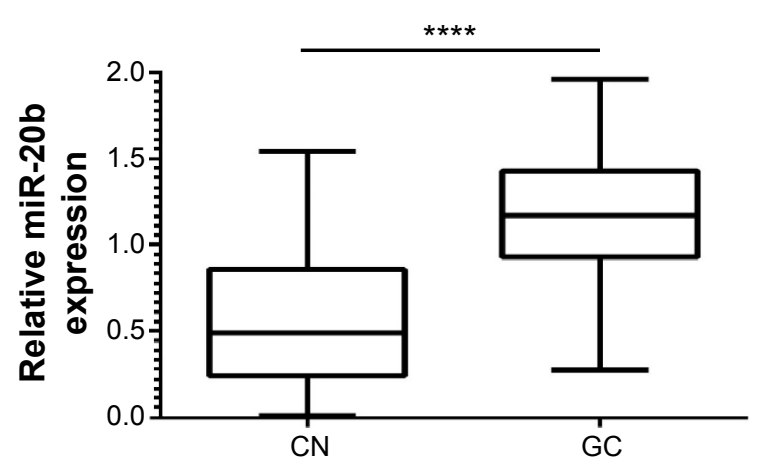

Figure 2 Comparison of miR-20b expression levels between GC tissues and adjacent non-cancerous tissues.

Note: $* * * * p<0.0001$.

Abbreviations: $\mathrm{CN}$, non-cancerous; GC, gastric cancer.

provide us with broad prospects to understand and overcome tumors in the future.

miR-20b belongs to the miR-106a-363 cluster, which together with the miR-17-92 and the miR-106b-25 clusters, forms a large family of highly similar miRNAs called the miR-17 family. ${ }^{17}$ In the present study, the high expression levels of miR-20b often promote tumor development, and thus miR-20b may serve as a potential oncogene. In our study, we found that miR-20b expression levels were significantly upregulated in GC cancer tissues compared with the normal adjacent tissues ( $P=0.00$, Figure 1). Furthermore, miR-20b expression showed a significant association with lymph node metastasis, TNM stage, and distant metastasis after a comparison of the clinicopathological factors; these parameters are all important clinical determinants for the prognosis of patients with GC. According to a Kaplan-Meier survival curve analysis, the OS rates of patients with GC indicated that high miR-20b expression was significantly correlated with poorer survival compared with low miR-20b expression. In a multivariate Cox model, we found that high miR-20b expression was an independent factor for the prediction of the 5-year OS of patients with GC. From the study on the clinicopathological characteristics, we found that the expression of miR-20b was upregulated in GC. High expression of miR-20b was significantly associated with tumor progression and decreased OS in patients with GC, which indicates that this miRNA might play a critical role in the development and progression of GC.
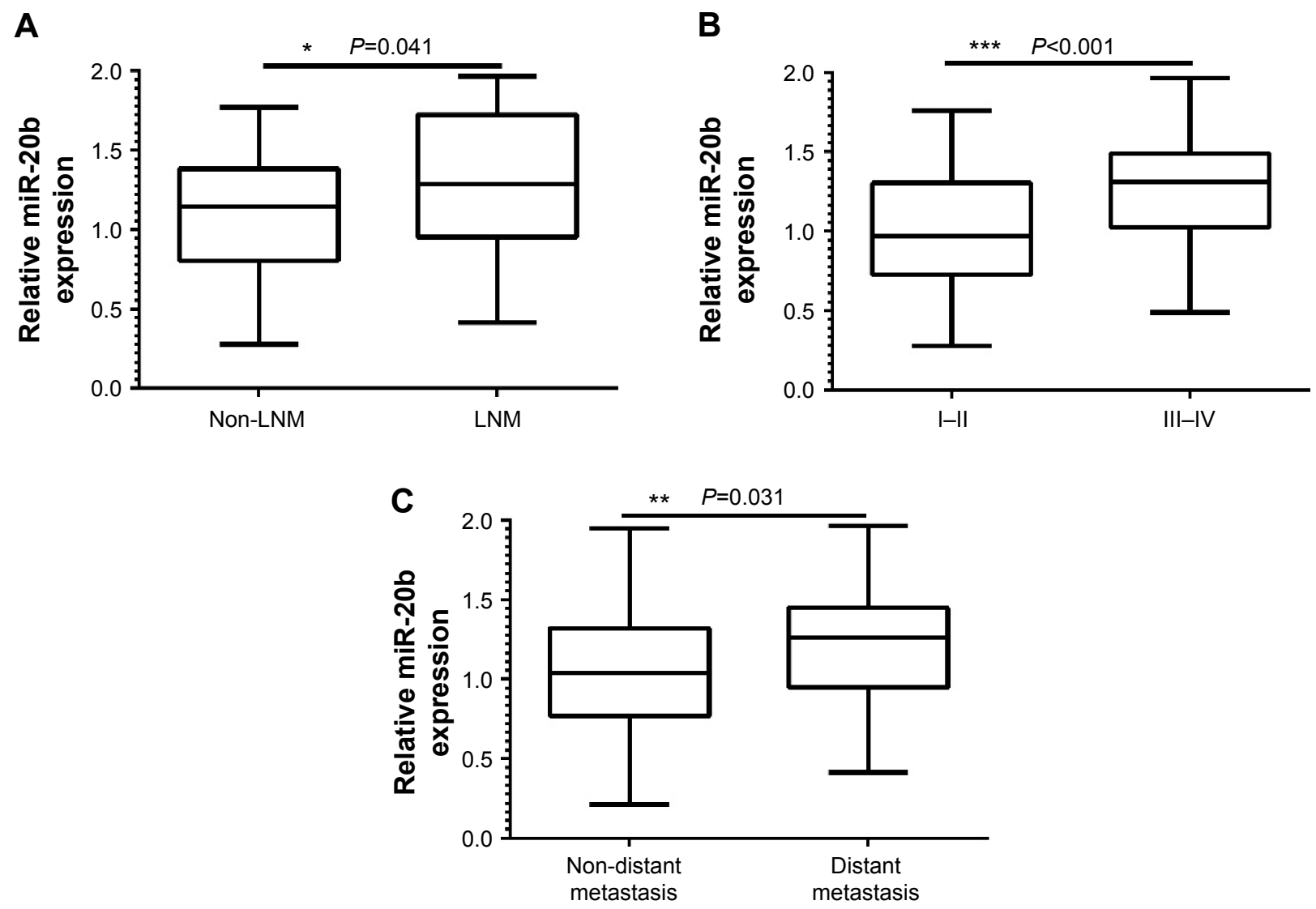

Figure 3 The correlation between the levels of miR-20b with tumor metastasis, TNM stage, and distant metastasis. Notes: (A) Lymph node metastasis ( $* P=0.041)$, (B) TNM stage $(* * * P<0.001)$, and $(\mathbf{C})$ distant metastasis $(* * P=0.031)$. Abbreviations: LNM, lymph node metastasis; TNM, tumor node metastasis. 


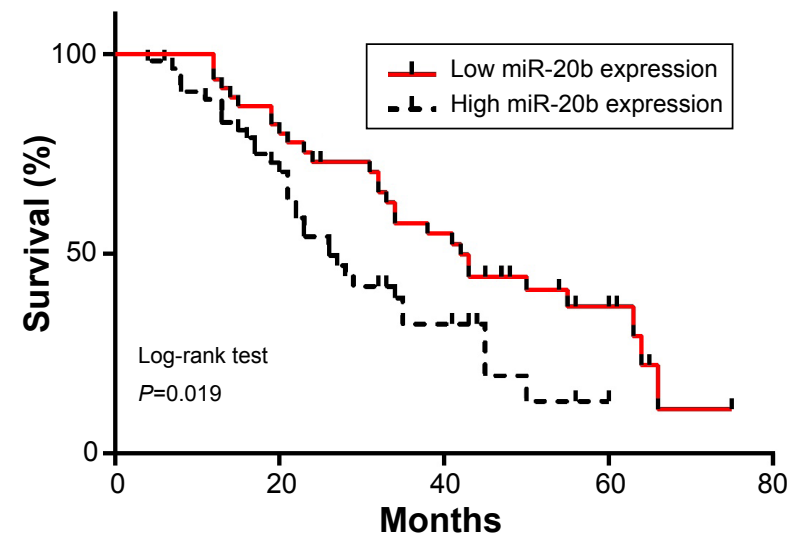

Figure 4 Kaplan-Meier survival curve of patients with GC.

Notes: Patients in the high expression group had a significantly poorer prognosis than those in the low expression group, as analyzed by log-rank tests as indicated $(P=0.019)$.

Abbreviation: GC, gastric cancer.

In our study, out of the 102 patients with GC, those whose tumors expressed a high level of miR-20b had a poor OS, while a higher expression of miR-20b suggests that miR-20b may be a prognostic and therapeutic marker in GC. High

Table 2 Univariate analysis of the clinicopathological factors for overall survival

\begin{tabular}{|c|c|c|c|c|}
\hline Variable & $\mathbf{n}$ & $\begin{array}{l}\text { Hazard } \\
\text { ratio }\end{array}$ & $95 \% \mathrm{Cl}$ & $P$-value \\
\hline \multicolumn{5}{|l|}{ Age (years) } \\
\hline$\leq 57$ & 54 & I & $0.385-1.445$ & 0.385 \\
\hline$>57$ & 48 & 0.746 & & \\
\hline \multicolumn{5}{|l|}{ Sex } \\
\hline Male & 71 & I & $0.431-1.645$ & 0.616 \\
\hline Female & 31 & 0.842 & & \\
\hline \multicolumn{5}{|c|}{ Tumor size $(\mathrm{cm})$} \\
\hline$\geq 3$ & 66 & I & $0.574-2.121$ & 0.768 \\
\hline$<3$ & 36 & 0.768 & & \\
\hline \multicolumn{5}{|c|}{ Invasion depth } \\
\hline $\mathrm{TI} / \mathrm{T} 2$ & 50 & I & $0.387-1.506$ & 0.436 \\
\hline $\mathrm{T} 3 / \mathrm{T} 4$ & 52 & 0.434 & & \\
\hline \multicolumn{5}{|c|}{ Lymph node metastasis } \\
\hline Yes & 67 & 1 & I.198-5.677 & $0.016 *$ \\
\hline No & 35 & 2.608 & & \\
\hline \multicolumn{5}{|c|}{ Pathological grade } \\
\hline GI/G2 & 66 & 1 & $0.334-1.175$ & 0.145 \\
\hline G3/G4 & 36 & 0.626 & & \\
\hline \multicolumn{5}{|l|}{ TNM stage } \\
\hline I-II & 55 & I & $0.131-0.620$ & $0.002 *$ \\
\hline III-IV & 47 & 0.285 & & \\
\hline \multicolumn{5}{|c|}{ Distant metastasis } \\
\hline Positive & 53 & I & I.109-4.645 & $0.025^{*}$ \\
\hline Negative & 49 & 2.273 & & \\
\hline \multicolumn{5}{|l|}{ miR-20b } \\
\hline High & 55 & I & $1.184-6.150$ & $0.018 *$ \\
\hline Low & 47 & 2.698 & & \\
\hline
\end{tabular}

Note: $* P<0.05$.

Abbreviations: TNM, tumor node metastasis; $\mathrm{Cl}$, confidence interval.
Table 3 Multivariate analysis of the clinicopathological factors for overall survival

\begin{tabular}{lclll}
\hline Variable & $\mathbf{n}$ & $\begin{array}{l}\text { Hazard } \\
\text { ratio }\end{array}$ & $\mathbf{9 5 \%} \mathbf{C l}$ & $P$-value \\
\hline $\begin{array}{l}\text { Lymph node } \\
\text { Yes }\end{array}$ & 67 & 1.161 & $0.475-2.837$ & 0.743 \\
No & 35 & & & \\
$\begin{array}{l}\text { TNM stage } \\
\text { I-II }\end{array}$ & 55 & 0.743 & $0.140-0.849$ & $0.020^{*}$ \\
III-IV & 47 & & & \\
$\begin{array}{l}\text { Distant metastasis } \\
\text { Yes }\end{array}$ & 53 & 0.642 & $0.275-1.498$ & 0.305 \\
$\begin{array}{l}\text { No } \\
\text { miR-20b }\end{array}$ & 49 & & & \\
High & 55 & 3.316 & $1.204-9.139$ & $0.020^{*}$ \\
Low & 47 & & & \\
\hline
\end{tabular}

Note: $* P<0.05$.

Abbreviations: TNM, tumor node metastasis; $\mathrm{Cl}$, confidence interval.

expression levels of miR-20b seemed to be a significant predictor for poor prognosis and development of metastasis. We found that the overexpression of miR-20b may promote lymph node metastasis because miR-20b was significantly increased in tumor tissues from patients with Stages III/IV compared with I/II, which means that patients with TNM Stage III/IV all had vascular invasion, this helps us understand why the high expression of miR-20b may be associated with tumor invasion. Based on the above study, we will investigate the mechanism by which miR-20b causes tumor invasion and metastasis in vitro. We will also study its targets and how they regulate the biological behavior of cells.

\section{Conclusion}

In conclusion, high expression levels of miR-20b in GC tissues were determined, and an extraordinary correlation between miR-20b expression and GC with respect to advanced lymph node metastasis, TNM stage, and distant metastasis was observed. In the present study, we report that miR-20b is associated with the poor OS of patients with GC, suggesting its potential prognostic value in this disease type.

\section{Acknowledgments}

This work was supported in part by grants from the Yangzhou scientific and technological project (YZ2014064) and the project sponsored by the Institute of General Surgical Research, Second Affiliated Hospital, Yangzhou University.

\section{Disclosure}

The authors have no conflicts of interest to disclose. 


\section{References}

1. Parkin DM, Bray F, Ferlay J, Pisani P. Global cancer statistics, 2002. CA Cancer J Clin. 2005;55(2):74-108.

2. Zhang S, Wu L, Liu Q, Chen K, Zhang X. Impact on growth and invasion of gastric cancer cell lines by silencing NEDD9. Onco Targets Ther. 2015; $8: 223-231$.

3. Cheng D, Liang B, Li Y. Serum galectin-3 as a potential marker for gastric cancer. Med Sci Monit. 2015;21:755-760.

4. Wang YW, Shi DB, Chen X, Gao C, Gao P. Clinicopathological significance of microRNA-214 in gastric cancer and its effect on cell biological behaviour. PLoS One. 2014;9(3):e91307.

5. Bartel DP. MicroRNAs: genomics, biogenesis, mechanism, and function. Cell. 2004;116(2):281-297.

6. He L, Hannon GJ. MicroRNAs: small RNAs with a big role in gene regulation. Nat Rev Genet. 2004;5(7):522-531.

7. Nelson P, Kiriakidou M, Sharma A, Maniataki E, Mourelatos Z. The microRNA world: small is mighty. Trends Biochem Sci. 2003;28(10): 534-540.

8. Chen P, Xi Q, Wang Q, Wei P. Downregulation of microRNA-100 correlates with tumor progression and poor prognosis in colorectal cancer. Med Oncol. 2014;31(10):235.

9. Ventura A, Jacks T. MicroRNAs and cancer: short RNAs go a long way. Cell. 2009;136(4):586-591.

10. Iorio MV, Croce CM. MicroRNAs in cancer: small molecules with a huge impact. J Clin Oncol. 2009;27(34):5848-5856.

11. Esquela-Kerscher A, Slack FJ. Oncomirs - microRNAs with a role in cancer. Nat Rev Cancer. 2006;6(4):259-269.

12. Ambros V. The functions of animal microRNAs. Nature. 2004;431(7006): 350-355.

13. Zhang Z, Sun J, Bai Z, et al. MicroRNA-153 acts as a prognostic marker in gastric cancer and its role in cell migration and invasion. Onco Targets Ther. 2015;8:357-364.

14. Cheung TH, Man KN, Yu MY, et al. Dysregulated microRNAs in the pathogenesis and progression of cervical neoplasm. Cell Cycle. 2012; 11(15):2876-2884.
15. Katada $\mathrm{T}$, Ishiguro $\mathrm{H}$, Kuwabara $\mathrm{Y}$, et al. microRNA expression profile in undifferentiated gastric cancer. Int J Oncol. 2009;34(2):537-542.

16. Lei Z, Li B, Yang Z, et al. Regulation of HIF-1alpha and VEGF by miR-20b tunes tumor cells to adapt to the alteration of oxygen concentration. PLoS One. 2009;4(10):e7629.

17. Zhou W, Shi G, Zhang Q, Wu Q, Li B, Zhang Z. MicroRNA-20b promotes cell growth of breast cancer cells partly via targeting phosphatase and tensin homologue (PTEN). Cell Biosci. 2014;4(1):62.

18. Ingwersen J, Menge $T$, Wingerath $B$, et al. Natalizumab restores aberrant miRNA expression profile in multiple sclerosis and reveals a critical role for miR-20b. Ann Clin Transl Neurol. 2015;2(1):43-55.

19. Yamaguchi T, Iijima $T$, Wakaume R, et al. Underexpression of miR126 and miR-20b in hereditary and nonhereditary colorectal tumors. Oncology. 2014;87(1):58-66.

20. Zhu J, Chen L, Zou L, et al. MiR-20b, -21, and -130b inhibit PTEN expression resulting in $\mathrm{B} 7-\mathrm{H} 1$ over-expression in advanced colorectal cancer. Hum Immunol. 2014;75(4):348-353.

21. Saleiban A, Faxalv L, Claesson K, Jonsson JI, Osman A. miR-20b regulates expression of proteinase-activated receptor-1 (PAR-1) thrombin receptor in melanoma cells. Pigment Cell Melanoma Res. 2014;27(3): 431-441.

22. Li JY, Zhang Y, Zhang WH, et al. Differential distribution of miR-20a and miR-20b may underly metastatic heterogeneity of breast cancers. Asian Pac J Cancer Prev. 2012;13(5):1901-1906.

23. Cascio S, D'Andrea A, Ferla R, et al. miR-20b modulates VEGF expression by targeting HIF-1 alpha and STAT3 in MCF-7 breast cancer cells. J Cell Physiol. 2010;224(1):242-249.

24. Wang CJ, Zhou ZG, Wang L, et al. Clinicopathological significance of microRNA-31, -143 and -145 expression in colorectal cancer. Dis Markers. 2009;26(1):27-34.
OncoTargets and Therapy

\section{Publish your work in this journal}

OncoTargets and Therapy is an international, peer-reviewed, open access journal focusing on the pathological basis of all cancers, potential targets for therapy and treatment protocols employed to improve the management of cancer patients. The journal also focuses on the impact of management programs and new therapeutic agents and protocols on

\section{Dovepress}

patient perspectives such as quality of life, adherence and satisfaction The manuscript management system is completely online and includes a very quick and fair peer-review system, which is all easy to use. Visit http://www.dovepress.com/testimonials.php to read real quotes from published authors. 